\title{
ANÁLISE \\ LINGUÍSTICA E \\ REESCRITA TEXTUAL: \\ ARTICULANDO \\ ENCAMINHAMENTOS
}

\section{ANÁLISIS LINGÜÍSTICO Y TEXTUAL REESCRITO: COORDINAR REFERENCIAS}

\author{
LINGUISTIC ANALYSIS AND TEXTUAL REWRITTING: ARTICULATING REFERRALS
}

Sueli Gedoz*

\begin{abstract}
RESUMO: Este artigo objetiva mostrar um estudo sobre a prática de análise linguística associada ao trabalho com a produção e a reescrita textual. Trata-se de uma investigação amparada na abordagem qualitativa interpretativista, recorrendo à perspectiva de cunho etnográfico e à pesquisa-ação como delineamento metodológico. Apresentamos encaminhamentos desenvolvidos a partir da produção textual em sala de aula, pautados na prática de análise linguística, entendida num enfoque que vai além do trabalho com a gramática normativa e que pode contribuir para o processo de produção e reescrita de textos. O recorte investigativo toma $\mathrm{o}$ texto, organizado num gênero discursivo, como ponto de partida e elemento norteador do ensino da Língua Portuguesa. A linha teórica utilizada ampara-se em fontes que conferem às práticas de análise linguística, produção e reescrita textual um viés dialógico no trabalho com a linguagem. Os resultados verificados indicam a necessidade de associação entre todas as práticas discursivas que organizam o ensino e mostram que a produção escrita e a reescrita textual são perpassadas e subsidiadas pela análise linguística.
\end{abstract}

PALAVRAS-CHAVE: Análise linguística. Produção textual. Reescrita.

RESUMEN: Este artículo tiene como objetivo mostrar un estudio sobre la práctica de análisis lingǘstico asociado al trabajo con la producción y la reescritura textual. Se trata de una investigación amparada en el abordaje cualitativo de interpretación, recorriendo la perspectiva de cuño etnográfico y la pesquisa-acción como delineamiento metodológico. Presentamos encaminamientos desarrollados a partir de la producción de textos en sala de aula, pautados en la práctica del análisis lingüístico, entendido con un enfoque que va más allá del trabajo con la gramática normativa, y que puede contribuir al proceso de producción y reescritura de textos. El recorte investigativo toma el texto, organizado en un género discursivo, como punto de partida y elemento orientador de la enseñanza de la lengua Portuguesa. La línea teórica utilizada se ampara en fuentes que confieren a las prácticas de análisis lingüístico, producción y reescritura textual una perspectiva dialógico en el trabajo con el lenguaje. Los resultados verificados indican la necesidad de asociación entre todas las prácticas discursivas que organizan la enseñanza y muestran que la producción escrita y reescritura textual son atravesadas y subsidiadas por el análisis lingüístico.

PALABRAS CLAVE: Análisis lingüística. Producción textual. Reescritura.

*Doutora em Letras. Professora da Secretaria de Estado da Educação do Paraná - SEED/PR e da União Educacional de Cascavel - UNIVEL, Cascavel/PR. E-mail: oi_sueli@hotmail.com. 
ABSTRACT: This article wishes to present a study about the practice of linguistic analysis associated to textual production and rewritings. It is about an investigation focused on a qualitative-interpretative approach, methodologically recurring to the ethnographic perspective and the active research. With it, we present referrals developed from in-class textual production, guided by the practice of linguistic analysis, understood as something that goes beyond the normative analysis, and which can contribute to the processes of textual production and rewriting. The investigative cut uses the text, organized in a discursive genre, as its starting point, and as the guiding element on the teaching of Portuguese. The verified results indicate the necessity of an association between all discursive practices that organize the teaching process, and prove that the textual production and rewriting are subsidized and pervaded by the linguistic analysis.

KEYWORDS: Linguistic analysis. Text production. Rewriting.

\section{INTRODUÇÃO}

O estudo apresentado neste artigo tem suas origens na prática da sala de aula, especialmente no que tange aos encaminhamentos com a análise linguística (AL doravante), associados à produção e à reescrita textual. As dúvidas em relação a encaminhamentos que ultrapassem os aspectos prescritivos e descritivos no ensino da língua são constantes para a maioria dos professores que atuam na docência da disciplina de Língua Portuguesa (LP, de ora em diante), pois, considerando o referencial teórico que passou a compor o cenário linguístico nos últimos trinta anos, é comum, na condição de docentes, verificarmos proposições que orientam sobre o que não fazer na sala de aula nos momentos destinados ao estudo da língua.

Conforme já salientamos em outras produções científicas, a crítica ao trabalho feito na prática da sala de aula e a proposição de soluções teóricas para o ensino são atividades que percebemos com muita frequência nos estudos linguísticos. Contudo, propostas de encaminhamentos práticos que direcionem o trabalho com a AL na escola, de acordo com perspectivas teóricas vigentes, ainda é uma tarefa executada por poucos.

Diante desse quadro, desenvolvemos um estudo com o intuito de apresentar a prática de AL como um encaminhamento que vai além do trabalho com a gramática e que pode contribuir para o processo de produção e reescrita de textos na sala de aula. Por tratarse de uma pesquisa bastante ampla, apresentamos neste artigo um recorte das ações executadas no processo investigativo.

Considerando esse objetivo, organizamos, inicialmente, uma apresentação dos conceitos teóricos que definem a AL, recorrendo a Geraldi (1984; 1997) para expor definições voltadas a essa prática discursiva. Além do referido autor, destacamos a consideração que os documentos oficiais estendem à $\mathrm{AL}$, recorrendo aos referenciais curriculares da esfera federal e da esfera estadual em que a pesquisa foi desenvolvida, neste caso, o estado do Paraná. O panorama conceitual delineado busca nos Parâmetros Curriculares Nacionais de Língua Portuguesa - PCN-LP (BRASIL, 1998) - e nas Diretrizes Curriculares da Educação Básica Língua Portuguesa - DCE-LP (PARANÁ, 2008) - o aporte para definir teórica e metodologicamente a AL no campo do ensino.

Seguido a isso, direcionamos as reflexões às articulações necessárias entre a AL e a produção e a reescrita textual, situando as práticas discursivas como encaminhamentos do ensino da LP perpassados a todo o momento pela AL, sendo esta última também considerada como uma prática discursiva. A seção focaliza o texto como ponto de partida e de chegada no ensino da língua e relembra os elementos essenciais, pontuados por Geraldi (1997), para qualquer situação de produção de texto desenvolvida em sala de aula. Após esse percurso teórico, o artigo expõe o percurso metodológico que delineou a pesquisa, apontando a abordagem qualitativa interpretativista, a perspectiva de cunho etnográfico e a pesquisa-ação como procedimentos que corroboraram os dados gerados. Na parte final do estudo, apresentamos um recorte de uma pesquisa desenvolvida com vistas à ratificação de que a prática de AL perpassa todas as demais práticas discursivas, especialmente a produção e a reescrita textual. 


\section{CONCEITOS TEÓRICOS QUE DEFINEM A ANÁLISE LINGUÍSTICA}

O trabalho com a prática de AL na sala de aula encontra respaldo teórico, especialmente, nas obras de Geraldi (1984,1997). O autor é referência nessa linha de estudo por ter cunhado o termo análise linguística, utilizado pela primeira vez no artigo que escreveu para compor a obra O texto na sala de aula, cuja primeira edição data de 1984. A proposição de Geraldi (1984) indicava, naquele momento, um olhar diferenciado para o que até então se propunha no trabalho com a língua. Até a década de 1980, trabalhar com a língua significava abordá-la apenas do ponto de vista descritivo e prescritivo, que focalizava o ensino de regras condizentes à gramática normativa e o conceito dos elementos da língua, partindo do fonema, avançando para a palavra e expandindo até a frase. Geraldi (1984) objetivou, de certa forma, ampliar essa perspectiva de trabalho, avançando para reflexões acerca dos diferentes usos da língua e, para isso, apresentou a necessidade de uma prática de AL, informando que, ao trabalhar nessa perspectiva, nos reportamos ao estudo da gramática tradicional e a questões relacionadas ao propósito do texto, como, por exemplo, coesão e coerência internas do texto, adequação do texto aos objetivos pretendidos e análise dos recursos expressivos utilizados, entre outros elementos.

Dessa forma, a proposta de Geraldi (1984) não excluía um trabalho com situações sistemáticas da língua. O diferencial estava na ênfase do trabalho com a reescrita, com o propósito de provocar, como ele mesmo disse, práticas reflexivas de AL. Nesse caso, trabalhar com a língua não se restringiria somente à metalinguagem, mas envolveria a leitura, a produção e a reescrita de textos por meio de um trabalho de reflexão sobre os recursos linguísticos.

É esse referencial que subsidia a prática de AL nos documentos curriculares criados após os estudos de Geraldi (1984, 1997), embora algumas proposições nesses referenciais curriculares não sejam tão claras para os docentes. Os Parâmetros Curriculares Nacionais de Língua Portuguesa - PCN-LP (BRASIL, 1998) - apresentam uma tentativa de inserção das práticas discursivas na teoria bakhtiniana, que tomava forças no Brasil na época da criação desse documento, mas não mantêm consistência teórica para o respaldo requerido. No que concerne às práticas de leitura, oralidade e escrita, a proposta defendida pelos PCN-LP indica essas práticas relacionadas aos diferentes gêneros discursivos como forma de ampliação da competência discursiva ${ }^{1}$ do aluno para o processo de interlocução. E nesse viés, o texto é visto como a unidade básica de ensino da Língua Portuguesa, opondo-se a concepções estruturalistas, pautadas em posições que tomam o estudo da língua a partir de encaminhamentos sintéticos, cujo movimento parte de unidades menores para unidades mais abrangentes.

Tomando o texto como unidade de ensino, a AL e as demais práticas discursivas são situadas nos eixos que orientam o ensino, sendo eles o uso da língua oral e escrita e a reflexão sobre a língua e a linguagem, evidenciando que "[...] as práticas de linguagem que ocorrem no espaço escolar [...] devem, necessariamente, tomar as dimensões discursiva e pragmática da linguagem como objeto de reflexão" (BRASIL, 1998, p. 34). O delineamento proposto direciona a AL à escuta, à leitura e à produção de textos orais e escritos, sendo tais práticas imersas, portanto, numa dimensão que considera os usos e as reflexões sobre a língua. Assim os PCN-LP reforçam que a AL não é uma nova denominação para o ensino da gramática, apontando-a como relacionada a todas as práticas de trabalho com a língua. No viés que situa a AL no texto, o documento propõe um trabalho com os gêneros, polarizando, primeiramente, os que fazem parte da esfera cotidiana do aluno, ampliando esse repertório para os gêneros de outras esferas, os quais podem ser utilizados pelos alunos em futuras situações de interação (profissionais, cotidianas, etc.).

Esse último encaminhamento proposto pelos PCN-LP também é percebido nas Diretrizes Curriculares da Educação Básica Língua Portuguesa - DCE-LP (PARANÁ, 2008). Utilizamos este documento neste estudo por se tratar do referencial que orienta o ensino da LP em nosso espaço de atuação. Caracterizado como um documento situado, historicamente, posterior ao contexto que deu origem aos PCN-LP, as DCE-LP apresentam-se como a proposta que atualmente direciona o ensino na esfera pública paranaense, no que tange aos anos finais do Ensino Fundamental e ao Ensino Médio. Num diálogo com a proposição indicada pelos PCN-LP, as DCE-LP admitem a necessidade de a escola possibilitar aos alunos o contato com a linguagem nas diferentes esferas

\footnotetext{
${ }^{1}$ De acordo com os PCN-LP, "Competência discursiva refere-se a um sistema de contratos semânticos responsável por uma espécie de filtragem que opera os conteúdos em dois domínios interligados que caracterizam o dizível: o universo intertextual e os dispositivos estilísticos acessíveis à enunciação dos diversos discursos" (BRASIL, 1998, p. 23).
} 
sociais, começando-se por legitimar as práticas sociais de linguagem próprias do cotidiano dos alunos. Isso colaboraria para "[...] a não fragmentação entre a língua e a vida do aluno, uma vez que na escola ele não leria e produziria apenas textos escolares, didatizados, mas teria contato com os textos presentes nos diversos espaços de socialização que frequenta (PARANÁ, 2008, p. 53).

No estudo que empreendem à AL, as DCE-LP também informam quais pressupostos teóricos organizam essa prática, bem como caracterizam-na, em seus encaminhamentos metodológicos, como uma prática a completar as demais (leitura, oralidade e escrita), visto inserir-se no letramento escolar. Para isso, o documento busca respaldo teórico em Mendonça (2006), informando que a AL possibilita "[...] a reflexão consciente sobre fenômenos gramaticais e textual-discursivos que perpassam os usos linguísticos, seja no momento de ler/escutar, de produzir textos ou de refletir sobre esses mesmos usos da língua” (MENDONÇA, 2006, p. 204). Em linhas gerais, para as DCE-LP, "[...] compreender os recursos que o texto usa e o sentido que ele expressa é refletir com e sobre a língua, numa dimensão dialógica da linguagem" (PARANÁ, 2008, p. 79). Assim sendo, a prática de AL é tomada a partir do contato que o aluno deve estabelecer com diferentes gêneros discursivos (orais e escritos), verificando as funções das construções linguísticas no interior do texto e os usos dessas construções na produção de sentidos.

Apresentados esses conceitos, situando nossa preocupação em defini-los a partir dos documentos oficiais que orientam o ensino, passamos então ao estudo teórico que direciona as articulações entre a prática de AL e a produção e a reescrita textual.

\section{A ANÁLISE LINGUÍSTICA E SUAS ARTICULAÇÕES COM A PRODUÇÃO E A REESCRITA TEXTUAL}

Tomada no viés que considera a linguagem como uma forma de interação, a prática de AL assume também um caráter dialógico, voltado aos sentidos do texto e aos significados produzidos pelas situações de interação. Partindo desse pressuposto, é inviável tratar a AL num contexto fragmentado e isolado das demais práticas discursivas, tal como ainda vem sendo observado em algumas situações na sala de aula. Assim, entendemos que as práticas discursivas (oralidade, leitura, escrita e reescrita) são atravessadas de forma inerente pela $\mathrm{AL}$, pois não há como desvincular, em qualquer gênero, os aspectos discursivos dos sentidos produzidos pelos elementos linguísticos que configuram a estrutura textual. Contudo, considerando o objetivo do presente trabalho, detemo-nos nas considerações à produção e à reescrita textual, tomando-as como práticas em que a AL se manifesta de forma evidente e necessária à condição dialógica que considera o texto como ponto de partida e de chegada no ensino da língua.

Situando a produção escrita nesse contexto, verificamos que o texto deve ser tomado como produto da interação entre sujeitos sociais responsivos, envolvendo-se nesse movimento, "[...] as intenções daquele que faz uso da língua para atingir o seu intento sem, contudo, ignorar que o leitor com seus conhecimentos é parte constitutiva desse processo" (KOCH; ELIAS, 2010, p. 34). A produção escrita deve ser entendida como um trabalho desenvolvido a partir de reais necessidades de interlocução. Autor e interlocutor atuam de forma dialógica nessa produção. O conceito de gênero discursivo passa a ser incorporado nas discussões que tratam a escrita como uma prática social dialogicamente constituída. A produção deve ser vista, portanto, como um trabalho consciente, com finalidade, interlocutores e gênero discursivo definidos. Essa é a concepção de produção escrita que, na atualidade, fundamenta teoricamente os documentos oficiais para o ensino da LP e articula encaminhamentos metodológicos para a prática na sala de aula. Trata-se de uma vertente que compactua com a teoria bakhtiniana o trato que concebe ao discurso e fornece subsídios para o enfoque atribuído à produção textual na sala de aula.

Para os PCN-LP, os encaminhamentos direcionados à produção textual devem considerá-la com a finalidade de formar escritores competentes capazes de produzir textos coerentes, coesos e eficazes, acenando, dessa forma, à articulação entre produção escrita e AL. Para isso, o documento toma os gêneros discursivos como objetos de ensino e reforçam a importância de um trabalho pautado na noção de gêneros, uma vez que "[...] a produção oral e escrita de textos pertencentes a diversos gêneros, supõem o desenvolvimento de diversas capacidades que devem ser enfocadas nas situações de ensino” (BRASIL, 1998, p. 24).

Para atender ao propósito de produção que considera os textos pertencentes a diversos gêneros, o documento sugere uma seleção de gêneros pautada nos textos que favorecem "[...] a reflexão crítica, o exercício de formas de pensamento mais elaboradas e abstratas, bem como a fruição estética dos usos artísticos da linguagem, ou seja, os mais vitais para a plena participação numa sociedade

Gedoz | Análise linguística e reescrita textual: articulando encaminhamentos 
letrada" (BRASIL, 1998, p. 24). Selecionados os gêneros, a preocupação recai também na forma de redigir os textos. O documento considera as condições de produção textual e elege quatro elementos essenciais nesse quesito: a finalidade, a especificidade do gênero, os lugares preferenciais de circulação e o interlocutor.

Numa linha de acepção que dialoga, em alguns pontos, com os PCN-LP, as DCE-LP também enfatizam as condições de produção como aspecto essencial para a escrita, ressaltando a "[... importância de o professor desenvolver uma prática de escrita escolar que considere o leitor, uma escrita que tenha um destinatário e finalidades [...]" (PARANÁ, 2008, p. 56). Outro ponto em comum com os parâmetros da esfera federal é a utilização de diferentes gêneros nas produções. Além dessas orientações, assumindo as proposições bakhtinianas também na produção escrita, as Diretrizes apontam para as peculiaridades de cada gênero discursivo que devem ser observadas na produção escrita, quais sejam: a composição, a estrutura e o estilo. Nesse quadro teórico informam que a posição defendida considera a prática da escrita como uma atividade que "[...] leva em conta a relação entre o uso e o aprendizado da língua, sob a premissa de que o texto é um elo de interação social e os gêneros discursivos são construções coletivas" (PARANÁ, 2008, p. 68).

Em alusão a Geraldi (1997), o documento prescreve a produção escrita como uma atividade interativa, que demanda elementos indispensáveis à sua realização. O produtor do texto assume o papel de locutor que escreve considerando o que tem a dizer, a razão para dizer, como dizer e os interlocutores para quem dizer. As DCE-LP sugerem que a produção textual só deve ser encaminhada após um trabalho amplo com determinado gênero discursivo. Além disso, é necessário definir o que será produzido (gênero), conhecer a esfera de circulação, delinear o objetivo para a escrita e prever os possíveis interlocutores. Ditas de outra forma, essas etapas correspondem ao que Geraldi (1997) significa como uma atividade de produção de texto, na diferenciação que estabelece entre produção de textos e redação. Explicando conforme o autor: "Nesta produzem-se textos para a escola; naquela produzem-se textos na escola" (GERALDI, 1997, p. 136). Destarte, a proposta ensejada pelas DCE-LP contempla os elementos essenciais para a produção de texto, conforme definidos por Geraldi (1997), quando afirma que, para a produção de texto, em qualquer modalidade, é necessário que:
a) se tenha o que dizer;
b) se tenha uma razão para dizer o que se tem a dizer;
c) se tenha para quem dizer o que se tem a dizer;
d) o locutor se constitua como tal, enquanto sujeito que diz o que diz para quem diz [...];
e) se escolham as estratégias para realizar (a), (b), (c) e (d) (GERALDI, 1997, p. 137).

Considerando o exposto pelo autor, entendemos a produção textual como uma prática dialógica que envolve processos e objetivos definidos. Um desses processos, aqui tomado também como prática discursiva, é a atividade de reescrita textual, a qual “[...] remete ao trabalho [...] realizado pelo autor do texto, quando retorna sobre seu próprio escrito e realiza algumas operações com a linguagem, que fazem com que o texto se modifique em vários aspectos possíveis" (FIAD, 2009, p. 2). Esse retorno ao texto, na sala de aula, deve ser mediado pelo professor por meio de diferentes estratégias que permitam ao aluno perceber que reescrever é interagir com o texto, baseando-se num processo reflexivo. Isso pode fazer com que se perceba que a escrita de texto e a sua reescrita caracterizamse como "[...] um momento no percurso desse processo, sempre possível de ser continuado" (FIAD; MAYRINK-SABINSON, 1991, p. 55). De acordo com Fiad e Mayrink-Sabinson (1991), os alunos devem compreender que toda produção pode ser repensada, reescrita e, ao tomarem conhecimento dessa situação, podem preocupar-se mais com seus textos e com a forma como os interlocutores os recebem. Além disso, é importante que entendam também que a reescrita tem papel fundamental na configuração textual, uma vez que o objetivo é tornar o texto mais claro e adequado à leitura, ou seja, à situação de interlocução. Esse trabalho realizado pelos discentes faz com que passem "[...] a considerar um texto escrito como resultado de um trabalho consciente, deliberado, planejado, repensado" (FIAD; MAYRINK-SABINSON, 1991, p. 63). Eis aí uma prática que inclui também a AL.

Ao analisarem linguisticamente seus próprios textos, os alunos terão condições de compreender que suas produções não estão acabadas, estão em processo de construção e podem sofrer alterações em sua estrutura. Na visão de Bakhtin (2000 [1979]), “[...] a reprodução do texto pelo sujeito (volta ao texto, releitura, nova execução, citação) é um acontecimento novo, irreproduzível na vida do texto, é um novo elo na cadeia histórica da comunicação verbal” (BAKHTIN, 2000 [1979], p. 332). 
Diante disso, não há como negar que a reescrita de textos produzidos no ambiente escolar deve ser uma prática constante, sistematizada e interativa, que considere aspectos linguístico-discursivos do texto produzido pelo aluno e, a partir desse olhar analítico, permita um trabalho sistematizado com a AL, objetivando a revisão das produções elaboradas.

No documento orientador da prática escolar na esfera paranaense, temos uma definição de reescrita textual que também sugere interação com a AL. Para as DCE-PR, a etapa destinada à revisão e à reescrita é o momento em que o aluno deve rever o texto escrito, observando as ideias, a finalidade, as características do gênero e o contexto de circulação. Na relação que estabelece entre AL e reescrita textual, o mesmo documento aponta para uma proposta de reescrita que considere aspectos textuais e discursivos, acenando para um trabalho de articulação entre as práticas discursivas. Para as DCE-LP, verificando os textos dos alunos, o professor pode selecionar atividades que reflitam e analisem os aspectos discursivos, textuais, estruturais e normativos do gênero trabalhado ${ }^{2}$.

Se considerarmos as práticas de produção e reescrita textual no viés da interação, que propõe um olhar dialógico para o texto, observando-o, criticando-o e analisando-o, estamos articulando a AL a essas práticas. Se alunos e professores analisam as dificuldades reveladas na produção escrita estão, necessariamente, aderindo ao estudo da AL no texto. Nisso, as práticas articulamse e atendem ao que Geraldi (1997) propõe como necessário à AL: é no texto do aluno e a partir desse texto (não em frases soltas) que a AL acontece e, dessa forma, o ensino da língua torna-se significativo. A proposição do autor considera como complementares o trabalho com a leitura, com a escrita e com a análise linguística, e aponta essa articulação como uma forma de condução à competência linguística.

\section{PERCURSO METODOLÓGICO}

Na tentativa de apresentar encaminhamentos teóricos e metodológicos que possam subsidiar práticas de AL associadas ao processo de reescrita textual, desenvolvemos uma pesquisa de cunho etnográfico, delineada pela pesquisa-ação, verificando nossa própria ação docente. O trabalho insere-se no âmbito da Linguística Aplicada (LA doravante), pois está relacionado a uma questão que envolve estudos da linguagem num contexto real, sendo este a sala de aula. De acordo com Cavalcanti (1986), as pesquisas ancoradas nessa abordagem iniciam com a detecção de uma questão específica de uso da linguagem, o que, na presente investigação, se configura na maneira como a prática de AL contribui com o processo de produção e reescrita de texto, de forma que constituam-se como práticas discursivas articuladas.

Diferentemente de pesquisas que buscam na prática a ratificação de uma teoria, as investigações ancoradas na LA contribuem para a elaboração de novas teorias que possam subsidiar encaminhamentos, os quais trazem novas possiblidades de análise da própria teoria. Nesse sentido, os pressupostos apontados por Cavalcanti dialogam com a proposta de Moita Lopes (1998), já que em “[...] LA a teoria informa a prática e a prática informa a teoria. A teoria que se quer é formulada interdisciplinarmente, mas é modificada pela prática” (MOITA LOPES, 1998, p. 110).

Além da inserção no campo da LA, o estudo realizado recorre a uma pesquisa qualitativa que, na acepção de Bortoni-Ricardo (2008, p. 34), “[...] procura entender, interpretar fenômenos sociais inseridos num contexto”. O ambiente da sala de aula é propício à manifestação de diversos fenômenos, sendo um deles as práticas de linguagem que investigamos neste trabalho. Na condição de docente-pesquisadora, atuamos conforme a perspectiva apontada pela autora: "O pesquisador está interessado em um processo que ocorre em determinado ambiente e quer saber como os atores sociais envolvidos nesse processo o percebem, ou seja: como o interpretam" (BORTONI-RICARDO, 2008, p. 34). Nesse enfoque, o tratamento teórico interpretativista também foi atribuído ao estudo, pois averiguamos fatos e fenômenos em sua profundidade e, para isso, utilizamos comparações e interpretações da prática

\footnotetext{
${ }^{2}$ Para as DCE-LP, tais aspectos são assim compostos: discursivos (argumentos, vocabulário, grau de formalidade do gênero); textuais (coesão, coerência, modalizadores, operadores argumentativos, ambiguidades, intertextualidade, processo de referenciação); estruturais (composição do gênero proposto para a escrita/oralidade do texto, estruturação de parágrafos); normativos (ortografia, concordância verbal/nominal, sujeito, predicado, complemento, regência, vícios da linguagem...) (PARANÁ, 2008, p. 79-80).
} 
social. Para Bortoni-Ricardo (2008, p. 32), nos estudos sob esse viés “[...] não há como observar o mundo independentemente das práticas sociais e significados vigentes", uma vez que "[...] a pesquisa interpretativista não está interessada em descobrir leis universais por meio de generalizações estatísticas, mas sim em estudar com muitos detalhes uma situação específica para compará-la a outras situações" (BORTONI-RICARDO, 2008, p. 42). Se o objetivo é compreender a dinâmica interna de fatos e fenômenos, nesse caso as contribuições das práticas de AL nos encaminhamentos de ensino da LP, especialmente a prática de produção e de reescrita dos textos, na condição de pesquisadora foi necessária a atuação no contexto social dos fatos, a fim de compreender a subjetividade dos sujeitos e a complexidade dos fenômenos.

Partindo dessa inserção metodológica, desenvolvemos uma pesquisa de campo, por meio da pesquisa-ação, em nosso espaço de atuação docente. A investigação foi realizada em uma turma do $7^{\circ}$ ano do Ensino Fundamental, durante o período de aproximadamente três meses, totalizando o acompanhamento de mais de 40 aulas na disciplina de LP. Para resgatar todas as informações geradas ao longo do período em que desenvolvemos a pesquisa-ação, utilizamos a gravação de aulas em áudio e vídeo ${ }^{3}$. Por meio desse último recurso, o contexto da sala de aula foi registrado, permitindo uma interpretação da forma como os sujeitos (alunos e professora) organizaram seus discursos, bem como as contribuições dessa organização para o propósito investigativo. Isso tudo atendeu ao que os estudos etnográficos solicitam das pesquisas qualitativas, ou seja, uma descrição das ações que envolvem os sujeitos da investigação. E para atender aos propósitos da pesquisa, utilizamos também a análise documental, considerando que, conforme corroborado por Lüdke e André (1986, p. 39), os documentos "[...] não são apenas uma fonte de informação contextualizada, mas surgem num determinado contexto e fornecem informações sobre esse mesmo contexto". Os textos produzidos e reescritos pelos alunos caracterizaram-se como documentos proeminentes para as análises empreendidas. No entender de Cellard (2008), a análise documental é pertinente quando a linguagem utilizada nos textos é um dos elementos fundamentais para a pesquisa, condição em que se inserem os textos produzidos e as atividades realizadas pelos alunos.

Neste artigo, temos o intuito de contextualizar a pesquisa e ressaltar as ações desenvolvidas em uma de suas etapas. O propósito é apresentar a prática de AL em consonância com a reescrita textual, definindo aquela prática como uma atividade inerente a todo o processo de trabalho com a língua na escola. As ações da pesquisa envolveram atividades com a oralidade, a leitura, a escrita, a reescrita e, automaticamente, a AL. Contudo, o foco recaiu nas três últimas práticas, dado o teor investigativo proposto.

Tomando os gêneros discursivos apresentados no planejamento anual dos conteúdos de Língua Portuguesa da turma do $7^{\circ}$ ano, elegemos um gênero para as atividades da pesquisa, escolhendo o gênero discursivo causo. Encaminhamentos explorando a oralidade foram realizados com o intuito de promover um contato inicial dos alunos com textos do gênero, ampliar o conhecimento sobre as características dos causos e proporcionar uma atividade de contação de histórias. Após isso, foram desenvolvidas atividades de leitura, focalizando a compreensão dos aspectos relacionados ao conteúdo temático e à construção composicional (BAKHTIN, 2004; 2011) de textos do gênero. Solicitando aos alunos que interpretassem, por escrito, alguns causos, procuramos direcionar a compreensão do contexto de produção e da função social do gênero, promover a interação dialógica com o texto e a coprodução de sentidos, intensificando outros conhecimentos acerca das peculiaridades dos causos. Ao trabalhar a leitura, elaboramos atividades que foram apresentadas aos alunos sob o rótulo da interpretação, mas que, no seu formato, exploraram os encaminhamentos da proposta bakhtiniana, numa tentativa de relacionar os trabalhos desenvolvidos na sala de aula com a investigação do gênero, além de verificar, no processo de leitura, algumas possibilidades de abordagem da AL.

Realizadas as atividades de oralidade e de leitura que, de certa forma, também exploraram as práticas de escrita e AL, orientamos os alunos a uma atividade sistematizada de produção textual, solicitando-lhes que pesquisassem, junto a familiares ou amigos, um causo e o recontassem por meio da linguagem escrita. Sem perder de vista o interlocutor da produção, os alunos foram informados de que os causos contados, após correções em sala de aula, seriam organizados em uma coletânea de causos, a qual seria disponibilizada para cada aluno e também passaria a compor o acervo literário da biblioteca do colégio. Os procedimentos resultantes da produção desenvolvida, relacionados à reescrita e à prática da AL, apresentamos na próxima seção deste artigo.

${ }^{3}$ A pesquisa teve início somente a partir da autorização da direção do colégio e dos pais dos alunos envolvidos no trabalho. 


\section{O TEXTO DO ALUNO E AS AÇÕES DE REESCRITA ASSOCIADAS À ANÁLISE LINGUÍSTICA}

Após a produção inicial, realizamos, em torno da escrita, diferentes atividades, privilegiando encaminhamentos que possibilitassem ao aluno revisões e análises diante de seu texto e procedesse à reescrita. Todo o trabalho desenvolvido foi com a intenção de demonstrar que a reescrita é o momento em que o aluno-autor torna-se um avaliador de seu texto ao dialogar com o enunciado produzido, criticando e intervindo na produção. O distanciamento entre a escrita e a reescrita permitiu que o autor se colocasse no lugar de um leitor avaliador e alimentasse o texto com intervenções que contribuíram para o encadeamento das informações.

Tomando esse pressuposto, transcorridos alguns dias da produção inicial, devolvemos os textos ( $1^{\text {a }}$ versão) aos alunos, juntamente com uma lista de controle/constatações (GONÇALVES, 2013). A lista de controle/constatações elaborada, atendendo ao gênero, indicava aspectos comuns a vários textos produzidos pelos alunos. Incluía, portanto, questões relacionadas à construção composicional e ao estilo dos textos do gênero causo, retomando também o seu conteúdo temático, já que esses elementos estão imbricados no estudo do gênero, conforme Bakhtin (2011 [1979]). Em posse da primeira versão de seus textos e da lista de controle/constatações, os alunos iniciaram uma análise da produção e fizeram marcações indicativas das intervenções que seriam necessárias na reorganização textual. Lançaram, então, ao próprio texto, um olhar avaliativo, colocando-se na posição de leitores que perscrutam a própria produção. Os alunos demonstraram grande concentração e empenho nessa tarefa, o que lhes proporcionou a compreensão mais apurada dos recursos linguísticos utilizados. Nessa atividade, a lista de controle/constatações foi elaborada pela professora e utilizada pelos próprios alunos como mecanismo de avaliação inicial dos textos, caracterizando-se como um instrumento "[...] de responsividade à primeira versão do texto" (GONÇALVES, 2013, p. 33), a qual pode ser verificada nos exemplos analisados na sequência.

Finalizada a tarefa de reescrita da primeira versão do texto, os alunos entregaram à professora a segunda versão, resultado da reformulação desenvolvida por meio dos elementos indicados na lista. De posse dessa versão, iniciamos um processo de tabulação de dados, lançando numa tabela diagnóstica as principais dificuldades que ainda se mostravam evidentes nas produções dos alunos. Partimos, então, para a segunda etapa do processo de reescrita. Para organizar os dados, utilizamos uma adaptação da tabela diagnóstica desenvolvida por Costa-Hübes $(2012)^{4}$ tendo em vista o gênero e o contexto da turma do $7^{\circ}$ ano. Justificamos a escolha dessa tabela por acreditarmos que tal instrumento evidencia as dificuldades apresentadas pelos discentes, traçando um panorama amplo dos aspectos não dominados em suas produções escritas. Por meio dela é possível direcionar atividades que possibilitem a superação das dificuldades apresentadas. Feita a tabulação dos aspectos não dominados na segunda versão do texto produzido, observamos quais desses aspectos mostraram-se evidentes na maioria dos textos e iniciamos um trabalho com a prática de AL, elaborando atividades a partir do texto do aluno, focalizando a superação dos pontos não dominados na escrita. A título de exemplificação, apresentamos aqui um dos encaminhamentos de AL desenvolvidos, que se pautou no texto do aluno Josés. Escolhemos esse texto por ser representativo de diversos aspectos não dominados pela turma.

O quadro abaixo indica o texto na segunda versão escrita pelo aluno, ou seja, a versão produzida após o trabalho com a lista de controle/constatações (GONÇALVES, 2013).

\footnotetext{
${ }^{4}$ A referida tabela diagnóstica foi elaborada pelo GELP - Grupo de Estudos de Língua Portuguesa -, vinculado ao Departamento de Educação da Associação dos Municípios do Oeste do Paraná - AMOP, e de acordo com Costa-Hubes (2012, p. 6) trata-se de um instrumento elaborado a partir de "[...] muitas discussões ocorridas com integrantes do grupo de estudos em 2009/2010, passando por várias adaptações, tendo em vista a concepção de linguagem, de gênero textual como objeto de estudo, de texto como unidade de ensino e dos aspectos linguístico-discursivos que permeiam os textos". 
Agora, verificando o que você marcou na tabela acima, reescreva seu texto corrigindo os aspectos que você acha que deve melhorar na sua escrita.

Bom trabalho!

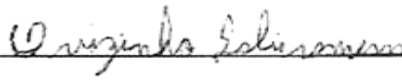

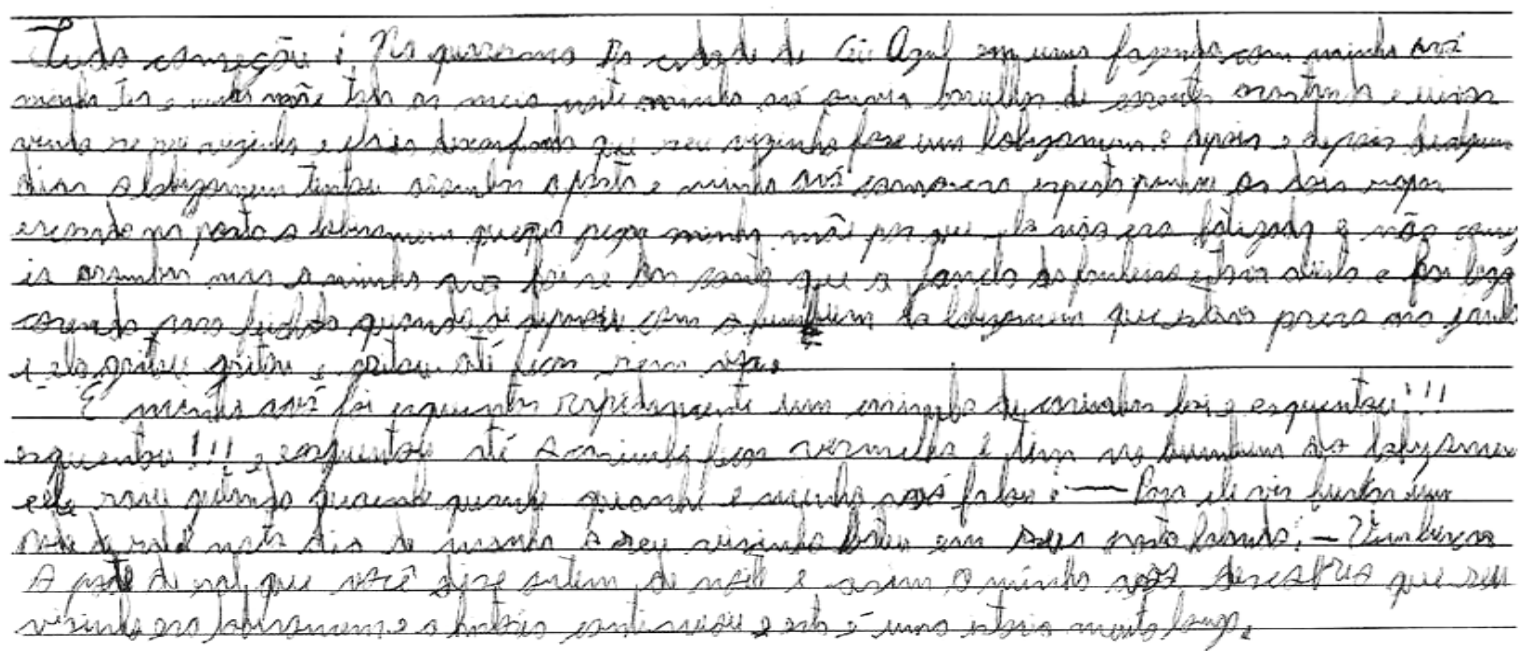

O vizinho Lobisomem

Tudo começou: Na quaresma na cidade de Céu Azul em uma fazenda com minha avó, minha tia e minha mãe toda as meia noite minha avó ouvia barulhos de corentes arastando e uivos vindo se seu vizinho e ela ia desconfiando que seu vizinho fose lobizomem e depois e depois de alguns dias o lobizomem tentou arombar a porta e minha avó como era esperta ponhou os dois sofás escorado na porta o lobisomem queria pega minha mãe porque ela não era batizada e não conseguia arombar mas a minha avó foi se dar conta que a janela do banheiro estava aberta e foi logo corendo para fechá-la quando de deparou com o bumbum do lobisomem que estava preso na janela e ela gritou gritou e gritou até ficar sem vos.

E minha avó foi esquentar rapidamente um carimbo de carimba boi e esquentou!!! esquentou!!! e esquentou até o carimbo ficar vermelho e tim no bumbum do lobisomem e ele saiu gritando quanhe quanhe quanhe e minha avó falou: Para ele vir buscar um pote de sal . e no dia de manhã o seu vizinho bateu em sua porta falando: _ Vim buscar o pote de sal que você dise ontem de noite e asim a minha avó descobrio que seu vizinho era lobisomem e a história continuou e esta é uma istória muito longa.

Fonte: dados gerados no decorrer da pesquisa (GEDOZ, 2015)

As dificuldades do aluno, no trato com a escrita, estão evidentes. É com produções desse nível que nos deparamos em muitos momentos do trabalho com a LP. Alunos com um traçado de letras quase ilegível, faltando-lhes noção de pontuação, paragrafação, ortografia e acentuação, bem como de elementos sintáticos responsáveis pela organização da textualidade (no nível semântico). Mas é esse aluno que precisa de recursos para ampliar suas possibilidades de escrita e, diante da reescrita produzida por José, selecionamos o seu texto para que todos pudessem refletir sobre algumas relações necessárias à organização textual.

As dificuldades básicas reveladas na escrita do aluno interferem na informatividade e, consequentemente, na progressão textual, a qual também é prejudicada pelo uso equivocado da pontuação. Feita a seleção da produção do aluno José, entregamos a todos os alunos da turma uma versão digitada do texto. Após leitura e identificação de alguns desajustes, informamos que passaríamos a um estudo sobre o texto de José, objetivando a reorganização da escrita. Tal estudo seria organizado em partes, conforme os parágrafos 
do texto. Todos os alunos receberam uma cópia do primeiro parágrafo, com algumas marcações feitas pela professora, para facilitar as atividades de AL. Nesse parágrafo corrigimos, antecipadamente, os problemas de ortografia e acentuação, visto que esses aspectos não seriam focalizados no momento do trabalho com a AL. O quadro seguinte demonstra o parágrafo estudado:

Quadro 2: Fragmento 1 - Texto do aluno José

\begin{tabular}{l}
\hline O vizinho lobisomem \\
$\mathbf{1}^{\mathbf{0}}$ parágrafo: \\
1Tudo começou: Na quaresma na cidade de Céu Azul em uma fazenda com minha avó, minha tia e minha máe toda a \\
meia noite minha avó ouyja barulhos de correntes arrastando e uivos vindo de seu vizinho e ela ia desconfiando que seu \\
vizinho fosse lobisomem depois de alguns dias o lobisomem tentou arrombar a porta e minha avó como era esperta \\
colocou os dois sofás escorados na portá lobisomem queria pegar minha mãe porque ela não era batizada e não conseguiu \\
arrombar masa minha avó foi se dar conta que a janela do banheiro estava aberta e foi logo correndo para fechá-la quando \\
se deparou com o bumbum do lobisomem que estava preso na janela e ela gritou gritou e gritou até ficar sem voz.
\end{tabular}

Fonte: elaborado pela pesquisadora (GEDOZ, 2015)

Seguido a esse quadro, imediatamente solicitamos a atividade abaixo:

Quadro 3: Atividades a partir do Fragmento 1 - Texto do aluno José

Atividades:
Vamos tentar deixar o texto mais um pouco mais claro?
1) Sem alterar a ordem das informações, tente reescrever o parágrafo dividindo-o em cinco partes conforme apontado pela
numeração colocada pela professora. Use ponto final para separar cada uma das partes e vírgulas onde julgar necessário.
Fonte: elaborado pela pesquisadora (GEDOZ, 2015)

A primeira atividade de AL explorada nesse exercício de reescrita chama a atenção dos alunos para a pontuação e, por esse motivo, foram sobrepostos numerais ao texto digitado. A intenção, ao trabalhar a pontuação nesse recorte do texto de José, era fazer com que os alunos percebessem o quanto a produção de sentidos pode ser prejudicada pela ausência dos sinais de pontuação e quão grande é o teor discursivo que esses sinais carregam. De acordo com Gedoz e Busse (2014, p. 244) “[...] A pontuação contribui para a organização das informações do texto e permite ao produtor estabelecer o encadeamento das ideias na construção de sentidos numa dada situação discursiva”, e essa construção discursiva provocada pela pontuação deve ser compreendida pelos alunos. Ao dispor no quadro 3 a atividade $n^{\circ}$, chamamos a atenção de todos para essa noção de discurso que deve ser inerente à pontuação.

Além de explorar esse elemento discursivo, também utilizamos a parte inicial do texto de José para trabalhar questões de informatividade, conforme observado nas atividades que seguem:

Quadro 3: CONTINUAÇÃO

2) Agora releia a parte inicial do texto:

"Tudo começou na quaresma, na cidade de Céu Azul..."

Sabemos que os causos não definem exatamente as datas dos acontecimentos, apenas utilizam-se de expressões como: "Há muito tempo atrás", "Numa época muito distante", "Antigamente". Então como podemos reescrever o trecho "Tudo começou na quaresma" para que passe a ideia de um tempo distante, não definido?

3) Agora observe o fragmento:

"...e depois de alguns dias o lobisomem tentou arrombar a porta..."

a) A expressão sublinhada nos dá ideia de:
(A) lugar
(B) personagem
(C) tempo 


\section{(D) espaço}

b) Releia o texto e tente responder: o lobisomem arrombou a porta alguns dias depois de qual acontecimento?

c) Por qual outra expressão poderíamos substituir a informação "depois de alguns dias"?

d) No trecho: “... lobisomem tentou arrombar a porta...”, de que porta se trata? Essa informação está presente no texto?

e) Reescreva o trecho apresentado na questão "d” acrescentando informações para torná-lo mais coerente.

4) Quando a avó foi fechar a janela do banheiro, encontrou lá o lobisomem. Por que o lobisomem estava preso na janela?

5) Na parte final desse parágrafo, percebemos um fato novo no texto: a reação da avó diante da atitude do lobisomem.

a) Em sua opinião:

( ) a avó gritou muito, até ficar rouca, porque estava com medo do lobisomem e nem lembrava que tinha deixado uma janela aberta.

( ) a avó gritou muito, até ficar rouca, principalmente porque lembrava que tinha deixado uma janela aberta e por isso estava com medo que o lobisomem entrasse pela janela.

( ) a avó gritou muito, até ficar rouca, principalmente porque estava com medo do lobisomem e depois ainda lembrou que havia uma janela aberta.

b) O texto nos permite essas três interpretações apresentadas acima. Então reescreva o trecho "...e minha avó gritou e gritou até ficar rouca, sem voz e ela tinha esquecido uma janela aberta" acrescentando as informações presentes na segunda alternativa do exercício anterior.

6) Agora, a partir de tudo o que você verificou nos exercícios anteriores, reescreva todo o parágrafo, fazendo as adaptações/correções necessárias. Releia as respostas que você deu aos exercícios e capriche na reescrita.

Fonte: elaborado pela pesquisadora (GEDOZ, 2015)

De uma forma geral, todas as atividades estão relacionadas às estratégias que tentam garantir a informatividade em um texto e, com isso, possibilitam sua progressão e textualidade (COSTA VAL, 1999). Se um dos quesitos necessários à informatividade é a suficiência de dados para que o texto seja compreendido com o sentido que o produtor pretende, é visto que José (e vários outros alunos da turma), não conseguiu atender a esse critério linguístico-discursivo na segunda versão da escrita, acenando para comprometimentos na progressão textual.

As atividade 2, 3(a), 3(b) e 3(c) exploram esse sentido da informatividade, porque recorrem ao uso de advérbios para garantir uma ampliação das informações já apontadas no texto. As questões 3(d) e 4 exploram a coerência proporcionada pelo nível de informatividade. Koch e Travaglia (2000, p. 81), amparados em Beaugrand e Dressler (1981), apontam que a informatividade exerce "[...] importante papel na seleção e arranjo de alternativas no texto, podendo facilitar ou dificultar estabelecimento de coerência”.

Quando projetamos uma pesquisa vislumbrando atividades de AL para subsidiar a reescrita textual, era esse enfoque que propúnhamos trabalhar e, aos poucos, fomos percebendo as possiblidades desse caminho. A escrita solicitada no exercício 6 revela que as atividades de AL (de 1 a 5 ) realmente subsidiaram os alunos para que ampliassem sua produção.

Os resultados colhidos com a atividade 6 mostram que, para a maioria dos alunos, o trabalho intenso com as dificuldades que exploram aspectos não dominados em suas produções amplia o reconhecimento das fragilidades que cada aluno possui em relação à escrita e faz com que reconheçam as possibilidades de reorganização do texto. Entretanto, para alguns alunos, especialmente 
aqueles que apresentaram muitos aspectos não dominados em seus textos, esse trabalho é lento, e exige ações que extrapolem o espaço da sala de aula ${ }^{6}$. José deu acenos de que as atividades de AL produziram resultados na reescrita de seu texto.

Quadro 4: Parágrafo reescrito por José (1º parágrafo)

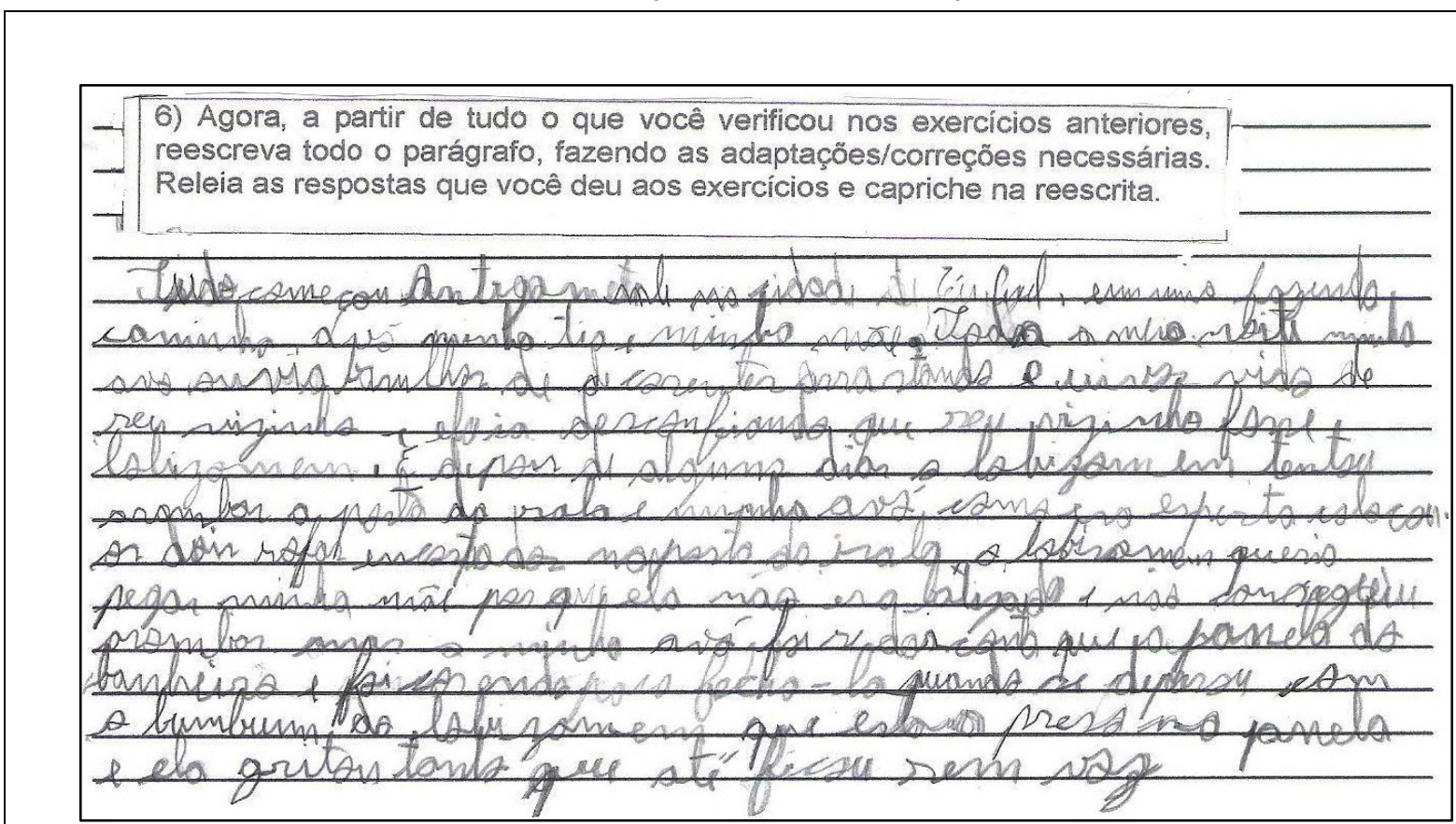

Tudo começou antigamente na cidade de Céu Azul, em uma fazenda caminha mãe, avó minha tia e minha mãe. Toda a meia-noite minha avo ouvia barulhos de de correntes arrastando e uivos vido de seu vizinho e ela ia desconfiando que seu vizinho fosse lobizomem. E depois de alguns dias o lobizomem tentou arombar a porta da sala e minha avó como era esperta colocou os dois sofás encostados na porta da sala. o lobisomem queria pegar minha mãe porque ela não era batizada e não conseguiu arombar, mas a minha avó foi se dar conta que a janela do banheiro e foi correndo fechá-la quando se deparou com o bumbum do lobizomem que estava preso na janela e ela gritou tanto que até ficou sem voz.

Fonte: dados gerados no decorrer da pesquisa (GEDOZ, 2015)

José insere em seu texto elementos próprios do gênero, como a marcação indeterminada de tempo, revelada no uso do advérbio "antigamente". Além disso, acrescenta aspectos que contribuem para a informatividade, conforme sugerido pelas atividades anteriormente realizadas. O trecho, “...o lobisomem tentou arrombar a porta...”, é reescrito situando o leitor acerca do espaço e tempo em que os fatos ocorrem, acrescentando a informação "E depois de alguns dias o lobizomem tentou arombar a porta da sala..." . Contudo, a compreensão de José pouco avança no quesito ortografia. O trecho mencionado é representativo da dificuldade do aluno, que ainda não conseguiu assimilar a escrita das palavras presentes no texto entregue pela professora $\left(1^{\circ}\right.$ parágrafo do texto de sua autoria) à sua própria escrita, pois continua mantendo a grafia das palavras lobizomem e arombar. Isso é compreensível, porque as atividades de AL desenvolvidas não rumaram para a exploração de aspectos ortográficos do texto. E, nesse sentido, compreendemos que a ortografia é um conteúdo que precisa ser efetivamente trabalhado para que o aluno vá construindo conhecimentos em relação à estrutura morfológica da palavra.

Se comparado às demais versões já escritas, o texto desse aluno acena para algumas alterações no plano da informação e da pontuação, aspectos explorados nas atividades realizadas. Lançando um olhar bastante positivo para o trabalho de José e considerando-se que se trata de um aluno com severas dificuldades na produção textual, as atividades desenvolvidas provocaramlhe interesse e certo conhecimento para realizar alterações em sua escrita, conforme visualizado no quadro abaixo.

${ }^{6}$ Referimo-nos aqui ao trabalho que é executado nas atividades de reforço escolar, em período contra turno, por exemplo. 
Quadro 5: Evolução da escrita de José - $1^{\circ}$ parágrafo do texto

\begin{tabular}{|c|c|c|}
\hline $1^{1}$ versão do texto & $\begin{array}{l}\text { Reescrita a partir da lista de } \\
\text { controle/constatações }\end{array}$ & Reescrita a partir das atividades de $\mathrm{AL}$ \\
\hline O vizinho Lobizomem & O vizinho Lobisomem & \\
\hline $\begin{array}{l}\text { Tudo começou: Na quaresma: na } \\
\text { cidade de céu Azul. em uma fazenda } \\
\text { com minha familia todas as meia noite } \\
\text { minha vó ouvia barulhos de corentes e } \\
\text { uivos vindo de seu vizinho e ela foi } \\
\text { desconfiando que seu vizinho era } \\
\text { lobizomem e depoisde quatro dia o } \\
\text { lobizomem tentou arombar a porta e a } \\
\text { minha vó tinha duas filhas uma delas } \\
\text { era minha mãe outra minha tia. } \\
\text { Uma delas era batizada minha tia e } \\
\text { minha mãe não era batizada e minha } \\
\text { avó gritou socoro até ficar sem vos e ela } \\
\text { tinha esquecido uma janela aberta. }\end{array}$ & $\begin{array}{l}\text { Tudo começou: Na quaresma na cidade de } \\
\text { Céu Azul em uma fazenda com minha avó, } \\
\text { minha tia e minha mãe toda as meia noite } \\
\text { minha avó ouvia barulhos de corentes } \\
\text { arastando e uivos vindo se seu vizinho e ela ia } \\
\text { desconfiando que seu vizinho fose lobizomem } \\
\text { e depois e depois de alguns dias o lobizomem } \\
\text { tentou arombar a porta e minha avó como era } \\
\text { esperta ponhou os dois sofás escorado na porta } \\
\text { o lobisomem queria pega minha mãe porque } \\
\text { ela não era batizada e não conseguia arombar } \\
\text { mas a minha avó foi se dar conta que a janela } \\
\text { do banheiro estava aberta e foi logo corendo } \\
\text { para fechá-la quando de deparou com o } \\
\text { bumbum do lobisomem que estava preso na } \\
\text { janela e ela gritou gritou e gritou até ficar sem } \\
\text { vos. }\end{array}$ & $\begin{array}{l}\text { Tudo começou antigamente na cidade } \\
\text { de Céu Azul, em uma fazenda caminha mãe, } \\
\text { avó minha tia e minha mãe. Toda a meia- } \\
\text { noite minha avo ouvia barulhos de de } \\
\text { correntes arrastando e uivos vido de seu } \\
\text { vizinho e ela ia desconfiando que seu vizinho } \\
\text { fosse lobizomem. E depois de alguns dias o } \\
\text { lobizomem tentou arombar a porta da sala e } \\
\text { minha avó como era esperta colocou os dois } \\
\text { sofás encostados na porta da sala. o } \\
\text { lobisomem queria pegar minha mãe porque } \\
\text { ela não era batizada e não conseguiu } \\
\text { arombar, mas a minha avó foi se dar conta } \\
\text { que a janela do banheiro e foi correndo } \\
\text { fechá-la quando se deparou com o bumbum } \\
\text { do lobizomem que estava preso na janela e } \\
\text { ela gritou tanto que até ficou sem voz. }\end{array}$ \\
\hline
\end{tabular}

Fonte: dados gerados no decorrer da pesquisa (GEDOZ, 2015)

Após esses encaminhamentos, foram desenvolvidas atividades relacionadas ao segundo parágrafo do texto de José, as quais rumaram novamente para a pontuação, a fim de garantir maior progressão textual. Mais uma vez, ao final do estudo do parágrafo, os alunos da turma foram convidados a reescrever o trecho, pautando-se nos encaminhamentos de AL desenvolvidos.

Toda a análise empreendida nos exercícios referentes ao texto de José foi organizada na tentativa de aliar AL à reescrita. Conforme nos orienta Geraldi (1984; 1997), para que a reescrita se caracterize num processo de interação do aluno com seu texto, é necessário que esse aluno adquira autonomia na revisão de sua produção, ação que acontece por meio de conhecimentos relacionados à AL. O autor informa que o trabalho com a AL deve tomar o texto, e não frases soltas, optando-se especialmente pelo texto do aluno, já que a prática de AL aliada à produção discente torna-se mais significativa. Nesse caminho, os textos produzidos em sala de aula fundamentam a prática de AL e esta, por sua vez, subsidia a reescrita.

\section{CONSIDERAÇÕES FINAIS}

O percurso apresentado nesta breve apresentação permite reconhecer que a produção textual desenvolvida em sala de aula requer um movimento dialógico, demarcando etapas essenciais à interação. A atitude responsiva do aluno que escreve e do professor que corrige/orienta é um fator que contribui com o processo de seleção de aspectos linguístico-discursivos que compõem o texto, direcionando a revisão e a reescrita.

Em se tratando dessa revisão que conduz a reescrita, os encaminhamentos apresentados desenham práticas de reescrita de texto que, inevitavelmente, são marcadas pela $\mathrm{AL}$, confirmando os postulados geraldianos de que essa prática deve partir de produções discentes, reveladoras de fragilidades linguístico-discursivas. A atenção que estendemos à lista de controle/constatações e à tabela 
diagnóstica revela que nossa ação de professora pesquisadora foi pautada em práticas que julgamos "possíveis” no âmbito da escola pública e dos anos finais do Ensino Fundamental.

Utilizando a lista de controle/constatações, percebemos que os alunos sentiram mais alento em relação às suas produções, por partilharem da confiança e da responsabilidade que, naquele momento, lhes foram atribuídas. Compreendendo o teor responsivo que a estratégia de reescrita requeria, lançaram um olhar investigativo sobre o texto, utilizaram da prática de AL para promover adequações e fortaleceram, especialmente, aspectos relacionados ao conteúdo temático e à construção composicional dos textos produzidos/reescritos.

Ao utilizar a tabela diagnóstica para visualizar aspectos linguístico-discursivos não dominados pelos alunos, também constatamos, por meio desse instrumento, a possiblidade de tonificar a associação tão necessária entre AL e reescrita. Ratificamos, assim, o postulado de que a produção do aluno é o caminho mais frutuoso para o provimento de informações acerca das fragilidades configuradas no processo de ensino da LP, isto é, a produção revela os conteúdos de ensino que necessitam de retomadas constantes e aqueles que podem/devem ser introduzidos no trabalho com a LP na sala de aula. Constatações obtidas por meio da tabela diagnóstica delinearam encaminhamentos que encontraram, na produção de José e de outros alunos da turma, possibilidades de trabalho com conteúdos próprios da $\mathrm{AL}$, os quais conduziram reflexões linguístico-discursivas nas atividades de reescrita desenvolvidas.

Acreditamos que o trabalho apresentado reitera a necessidade e a importância de que os encaminhamentos de reescrita textual sejam subsidiados pela prática de AL. As reflexões mostram que a pretensão de todo o percurso desenvolvido não foi, em qualquer momento, demonstrar uma inovação no trato da AL, da produção e da reescrita na escola. A intenção resume-se em demonstrar possibilidades de como agir a partir da teoria exposta para o ensino da LP, tentando assegurar nas ações empreendidas uma perspectiva dialógica de trabalho com a linguagem.

\section{REFERÊNCIAS}

BAKHTIN, M. [1979]. Estética da criação verbal. Tradução de Paulo Bezerra. 6. ed. São Paulo: WMF Martins Fontes, 2011.

; VOLOCHINOV. [1929]. Marxismo e filosofia da linguagem. Tradução de Michel Lahud \& Iara Frateschi Vieira. 11. ed. São Paulo: Hucitec, 2004.

BORTONI-RICARDO, S. M. O professor pesquisador: introdução à pesquisa qualitativa. São Paulo: Parábola Editorial, 2008.

BRASIL. Ministério de Educação e do Desporto. Secretaria de Educação Fundamental. Parâmetros curriculares nacionais: terceiro e quarto ciclos do Ensino Fundamental: introdução aos parâmetros curriculares nacionais. Brasília: MEC/SEF, 1998.

CAVALCANTI, M. C. A propósito de linguística aplicada. Trabalhos em Linguística Aplicada, n.7, p. 5-12, 1986.

CELLARD, A. A análise documental. In: POUPART, J. et al. A pesquisa qualitativa: enfoques epistemológicos e metodológicos. Tradução de Ana Cristina Nasser. Petrópolis: Vozes, 2008. p. 295-316.

COSTA-HÜBES, T. da C. Análise de textos de alunos dos anos iniciais: orientações para um possível diagnóstico. Work. pap. linguíst., Florianópolis, v. 3, n. 13, p. 1-20, out./dez., 2012.

COSTA VAL, M. da G. Redação e Textualidade. São Paulo: Martins Fontes, 1999. 
FIAD, R. S. A pesquisa sobre a reescrita de textos. In: SIMPÓSIO MUNDIAL DE ESTUDOS DE LÍNGUA PORTUGUESA, 2009, Évora. Anais... Portugal: Universidade de Évora, 2009. p. 1-9.

; MAYRINK-SABINSON, M. L. T. A escrita como trabalho. In: MARTINS, M. H. et al. (Org.). Questões de linguagem: muito além do português. São Paulo: Contexto, 1991.p. 54-63.

GEDOZ, S. Prática de análise linguística no trabalho com gêneros discursivos: em foco, a produção e a reescrita textual. 2015. $274 \mathrm{f}$. Tese (Doutorado em Letras) - Universidade Estadual do Oeste do Paraná - UNIOESTE, Cascavel/PR, 2015.

; BUSSE, S. A pontuação e seus efeitos de sentido: elementos para a leitura. In: COSTA-HÜBES, T. da C. et al. Descritores da Prova Brasil (5ªno): estudos e proposições didáticas. São Carlos: Pedro \& João Editores, 2014. p. 243-262.

GERALDI, J. W. Portos de passagem. 4. ed. São Paulo: Martins Fontes, 1997.

. Concepções de linguagem e ensino de Português. In: (Org.). O texto na sala de aula. Cascavel: Assoeste, 1984. p. 41-48.

GONÇALVES, A. V. As Listas de controle/constatações como ferramentas para a reescrita de gêneros In: GONÇALVES, A. V.; BAZARIM, M. (Org.). Interação, gêneros e letramento: A (re)escrita em foco. Campinas: Pontes Editores, 2013. p. 21-34.

KOCH, I. V.; ELIAS, V. M. Ler e compreender: os sentidos do texto. 3. ed. São Paulo: Contexto, 2010a.

KOCH, I. G. V.; TRAVAGLIA, L. C. Texto e coerência. 7. ed. São Paulo: Cortez, 2000.

LÜDKE, M.; ANDRÉ, M. E. D. A. Pesquisa em educação: abordagens qualitativas. São Paulo: E.P.U, 1986.

MENDONÇA, M. Análise linguística no ensino médio: um olhar, um outro objeto. In: BUNZEN, C.; MENDONÇA, M. (Org.). Português no ensino médio e formação de professor. São Paulo: Parábola Editorial, 2006. p. 199-226.

MOITA LOPES, L. P. A transdiciplinaridade é possível em Linguística Aplicada? In: SIGNORINI, I.; CAVALCANTI, M. C. (Org.). Linguística aplicada e transdiciplinaridade: questões e perspectivas. Campinas: Mercado das Letras, 1998. p. 101-114.

PARANÁ. Secretaria de Estado da Educação. Departamento de Educação Básica. Diretrizes Curriculares da Educação Básica Língua Portuguesa. Curitiba: SEED-PR, 2008. 